\title{
Comments on 'Hereditary Neuropathy with Liability to Pressure Palsy: An Investigation in a Rare and Large Chinese Family'
}

\author{
Hervé Delacour Aurore Bousquet Sarah Bugier Franck Ceppa \\ Unit of Genetics, Department of Biology, Bégin Military Teaching Hospital, Saint Mandé, France
}

\section{Dear Sir,}

We read with interest the article by $\mathrm{He}$ et al. [1] about the investigation of hereditary neuropathy with liability to pressure palsies (HNPP) in a large Chinese family. The authors described a 43-member family that included 10 suspected patients among 4 generations. However, they mentioned that no patient was observed in the fourth generation and speculated that it might be due to the young age of these patients or the presence of asymptomatic patients.

As underlined by the authors, the onset of HNPP symptoms usually occurs in the second or third decade of life and, clinically, HNPP patients usually display phenotypic heterogeneity, some patients being asymptomatic. In this context, electrophysiological examination (EPE) is of great importance. A simple standard EPE is sufficient to identify altered PMP22 gene carriers before the onset of the first HNPP episode. Bilaterally delayed distal motor latencies and reduced sensory velocity in the palm-wrist segment and a delayed distal motor latency or reduced motor nerve conduction velocity in the peroneal nerve are highly suggestive of the disease when there is a family history of HNPP [2]. Thus, an EPE should be performed in the 2 high-risk patients of the fourth generation (i.e. the patients having a father suffering from HNPP) to identify if they carry an altered PMP22 gene or not. Preventive measures (e.g. the use of protective elbow and knee pads) should be proposed to those identified as carrying the genetic defect.

Moreover, a HNPP diagnosis in a serviceman, as the proband in the article, may lead to the questioning of his ability. The final decision (partial or total disability) should be considered on an individual basis taking into account the history of the disease (unique or repeated episodes) and the patient's type of job [3]. It should be interesting to know if the patient was declared unfit for service or not.

\section{References}

1 He Y, Wu Q, Xu Z, Wang Q, Wang W, Li D, Liu W, He X: Hereditary neuropathy with liability to pressure palsy: an investigation in a rare and large Chinese family. Eur Neurol 2012;68:322-328.

-2 Dubourg O, Mouton P, Brice A, LeGuern E, Bouche P: Guidelines for diagnosis of diagnosis of hereditary neuropathy with liability to pressure palsies. Neuromuscul Disord 2000; 10:206-208.

3 Delacour H, Bompaire F, Biale L, Sallansonnet-Froment M, Ceppa F, Burnat P: Hereditary neuropathy with liability to pressure palsies occurring during military training. J $\mathrm{R}$ Army Med Corps 2012;158:47-49.

\section{KARGER}

E-Mail karger@karger.com www.karger.com/ene (c) 2013 S. Karger AG, Base

0014-3022/13/0706-0364\$38.00/0
Hervé Delacour

Unit of Genetics, Department of Biology, Bégin Military Teaching Hospital 69, avenue de Paris

FR-94 163 Saint Mandé Cedex (France)

E-Mail herve.delacour@santarm.fr 